\section{Relaciones científicas de medicina veterinaria venezolana con sus pares latinoamericanos: México y el Cono Sur $(1933-1955)^{*}$}

Scientific links between Venezuela's veterinary medicine and its Latin American counterparts: Mexico and the Southern Cone (1933-1955)
Yajaira Freites

Investigador asociado del Departamento de Estudio de la Ciencia Instituto de Investigaciones Científicas Departamento d Estudio de la Ciencia Instituto Venezolano de Investigaciones Científicas 20632 Caracas 1020a - Venezuela yafreites@yahoo.es
FREITES, Yajaira. Relaciones científicas de medicina veterinaria venezolana con sus pares latinoamericanos: México y el Cono Sur (1933-1955). História, Ciências, Saúde - Manguinhos, Rio de Janeiro, v.15, n.2, p.497-518, abr.-jun. 2008.

Resumen

En este trabajo se describe como las relaciones entre Venezuela, Argentina, Uruguay y México se vincularon a la construcción de una capacidad endógena del primero en el campo de la medicina veterinaria. La influencia de los países en cuestión ocurre en diversas etapas del crecimiento de la comunidad de veterinarios en Venezuela. El artículo expone una experiencia de como las relaciones científico-técnicas no siempre proceden según el esquema centroperiferia (sociedad desarrollada a periférica), sino que pone en evidencia la existencia de sociedades periféricas que pueden actuar como referentes o intermediarios para la transferencia de los saberes.

Palabras clave: salud animal; aftosa; educación; centro periferia; América Latina.

Abstract

The bonds established by Venezuela from 1933 to 1955 with Argentina, Uruguay and Mexico formed the groundwork for the Venezuelan State's efforts to foster knowledge and skills in the field of veterinary medicine. The countries in question exerted an influence at different stages in the growth of the veterinary community in Venezuela. This study describes an experience of how scientific and technical ties are not always forged along center-periphery lines, showing that there are peripheral societies capable of operating as points of reference or intermediaries in the transfer of knowledge.

Keywords: Animal health; foot-and-mouth; education; center periphery; Latin America. 
$\mathrm{P}$ or lo general, en la historia de la ciencia en América Latina ha habido la tendencia a estudiar la influencia científica y tecnológica proveniente de los países centrales, tales como Inglaterra, Francia, Alemania o los Estados Unidos (Cotter, 1994; Cueto 1994; Espina, 1997; Fitzgerald, 1994; McCook, 2000, 2002; Petitjean, 1992; Pyenson, 1982; Safford, 1972, 1976), obviando aquellos que aun en el esquema centro-periferia tienen el papel de intermediarios en una misma región. ${ }^{1}$ Las relaciones científicas y técnicas entre los propios países de América Latina es un tema poco explorado en la región; en parte porque ellas han surgido esporádicamente o, en cualquier caso, es un asunto focal en ciertas disciplinas y/o situaciones como la aquí examinada. Este trabajo es el principio de una exploración en tal sentido, centrando la atención en el caso de la medicina veterinaria en Venezuela.

El inicio de la relación de Venezuela con países de la propia región comienza a mediados de los años 30 del siglo XX, cuando el Estado venezolano estaba interesado en incorporar personal con conocimientos y destrezas científicas en el campo de la veterinaria y exploró la posibilidad de obtener asesoría y/o contratar profesionales capacitados en aquellos países que los tuvieran. Fue así como en un primer momento el gobierno venezolano del entonces dictador Juan Vicente Gómez (1908-1935) y luego el de su sucesor, Eleazar López Contreras (1936-1940), consideraron hallarlos en países de la región del Cono Sur, concretamente Argentina, Chile y Uruguay. Luego, a partir de finales de la década de 1950, se incorporó México. Este último momento coincidió con la expansión de la fiebre aftosa por la región y con el inicio de los sistemas regionales referentes a la salud animal.

En este trabajo interesa detallar los diferentes momentos de la relación, las modalidades y los logros de la misma, a la par que se examina el crecimiento de la veterinaria en el país. Para ello se hace uso de diversas fuentes documentales y bibliográficas relativas a la veterinaria en Venezuela.

\section{La modernización del mundo agropecuario venezolano}

En la década de 1930, la crisis económica mundial afectó a la sociedad venezolana, especialmente la vinculada al comercio agro exportador, llevando a la ruina a los agricultores venezolanos. El gobierno del entonces general Juan Vicente Gómez ${ }^{2}$ impulsó una serie de medidas tales como los préstamos bancarios para el rescate de sus tierras, ayuda crediticia y el establecimiento de servicios estatales destinados a incentivar una agricultura y ganadería basada en principios científicos con miras a la exportación (Rodríguez, 1983).

La creación de los servicios, además de la consiguiente organización de unidades en el campo, laboratorios, implicaba contar con personal profesional que no existía en el país como eran los del área de la veterinaria y agronomía que en cierta forma tenían la responsabilidad de crearlos y poner en marcha los servicios. El asunto fue solventado con la contratación de expertos extranjeros y fueron preferidos aquellos provenientes de países afines con Venezuela así como que dominasen el castellano, pues también se preveía que este personal extranjero participaría en la formación de personal técnico nativo. Para ello se fundó la Escuela de Expertos-Agropecuarios (1932), donde se pretendía formar tanto a personal dedicado al agro como a la producción pecuaria. Una revisión del pensum revela que los estudios relativos a la producción pecuaria tenían menos materias que los de 
agronomía. También en esa época el propio Gómez, de manera indirecta, propició en el área privada otra iniciativa.

\section{La primera industria cárnica}

A instancias de un grupo de particulares, entre los que se encontraban los hijos del presidente de entonces, el general Gómez, así como otras figuras connotadas de la política de entonces, se creó la Compañía Ganadera Industrial Venezolana, S.A. (1934-1942). La empresa, estaba orientada al procesamiento industrial de productos cárnicos. Dado que se trataba de una actividad en la cual el país carecía de experiencias previas, la compañía envió a uno de sus empleados de confianza al Uruguay a estudiar los procedimientos. Como consecuencia de ello, transfirió esos nuevos conocimientos, así como otros, los cuales serían usados bajo el pago de patente, siendo incorporados al proceso industrial de la empresa (Información..., 1934). La compañía usó para el procesamiento de la carne el sistema Tabáres, procedente del Uruguay, a través del pago de la patente Artigas (Juzgado de Comercio, 1934, p.11).

El dueño de la patente, Ramón Tabáres hijo, vino al país, adquirió varias de las acciones de la empresa y tuvo a su cargo la compra en Estados Unidos de las maquinarias para la factoría, asentada en la ciudad de Maracay. Al parecer, él había desempeñado similares actividades en instalaciones de Uruguay y Brasil. También llegaron del Uruguay un grupo de expertos bajo cuya dirección empezaron a funcionar los diferentes departamentos de la industria, mientras se entrenaban a los técnicos y obreros venezolanos. La meta de los socios era que la empresa tuviese instalaciones similares a las de Argentina, Uruguay y Brasil (La Compañía..., 1934).

\section{La contratación de personal extranjero}

Al principio, el gobierno de Gómez contrató profesionales extranjeros; en el caso de la veterinaria, cuatro médicos veterinarios ingresaron al país, el primero de ellos era de origen checo, Vladimir Kubes, quien había estado en Ecuador creando los servicios de salud animal y dominaba el castellano. Los otros eran el chileno Carlos Otto y los argentinos, Emilo Graña y Fernando Roumigüire. Un quinto vino por su propia cuenta, el uruguayo Guillermo Vogelsang.

Kubes, se encargó de dictar el primer curso de sanidad animal. Cuando se impartió el segundo curso ya Kubes había escrito el primer texto de veterinaria en el país, titulado II Curso de Prácticos de Salubridad Animal (1934-1935). Ambos hechos, el curso como el texto, constituyeron el primer entrenamiento más sistemático en la veterinaria que hubo hasta ese entonces.

Otto viajó por todo el país y junto con Kubes realizó un diagnóstico de las enfermedades que aquejaban al rebaño nacional; Otto también realizó una labor divulgativa, dictando conferencias en los centros ganaderos. Por su parte, Graña y Roumigüire estuvieron más activos entre 1936 a 1937. Este último estuvo relacionado con los aspectos zootécnicos; en tanto Graña fue uno de los fundadores de la Escuela Superior de Veterinaria (1938), siendo su primer director. 
El uruguayo Vogelsang por su propia cuenta trabajó como médico veterinario en el Hipódromo de Caracas e ingresó en el ejército como asimilado, alcanzando el rango de coronel; tempranamente, en 1931, dio rienda a su vocación docente en la Escuela Práctica de Agricultura localizada en Maracay. Vogelsang se radicaría en Venezuela, Kubes permanecería unos 15 años $^{3}$, en tanto Otto, Roumigüire y Graña regresarían a sus países de origen (Freites, 1999).

\section{La formación de veterinarios venezolanos en el Cono Sur}

Con la muerte del general Gómez en 1935, el también general López Contreras le sucede, pero éste emprende un proceso de modernización de la sociedad venezolana. ${ }^{4}$ La política de incentivar una agricultura y ganadería basada en principios científicos fue continuada pero ya el objetivo fue abastecer el mercado interno. Se buscaba, en el caso de la producción pecuaria, que la sanidad animal fuera extendida a todo el territorio, razón por la cual los servicios veterinarios debían de contar con mayor personal para su funcionamiento. No bastaba la contratación de personal extranjero o la simple formación de técnicos nacionales sino de profesionales universitarios venezolanos en el área de la agronomía y la veterinaria. Se diseñó una doble estrategia. La primera, crear las respectivas Escuelas Superiores de Agronomía y Veterinaria (1938), apoyándose en una mezcla de médicos y veterinarios extranjeros. La segunda parte de la estrategia consistía en enviar a jóvenes venezolanos a estudiar veterinaria en las escuelas de veterinaria de Argentina, en las Universidades de La Plata y de Buenos Aires, y en la Universidad de la República, en Uruguay. Así entre 1936 a 1945, 33 jóvenes obtuvieron su titulo de veterinario en Argentina y en Uruguay. El mayor número de becarios graduados correspondió al Uruguay. A partir del 1946, cesó el programa de pregrado en el exterior (Freites, 1999).

En 1945, con motivo de la toma del gobierno por una combinación de jóvenes militares y políticos del partido Acción Democrática (1945-1947) se nombraron a profesionales venezolanos de agronomía y veterinaria en los puestos directivos del Ministerio de Agricultura y Cría (MAC); casi todos ellos se habían formado en las universidades argentinas de La Plata y Buenos Aires. ${ }^{5}$

\section{La transferencia de un modelo educativo}

Con la creación de la Escuela Superior de Veterinaria (1938) se separa definitivamente la disciplina del binomio que hasta ese entonces la había asociado a la agronomía pero en condiciones de minusvalía. La escuela venezolana de veterinaria habría tomado como modelo de referencia a su homónima en La Plata (Argentina), transfiriendo el pensum de aquella. Empezaba el conocimiento del caballo al igual que en La Plata y los estudios terminaban con la presentación de una tesis. ${ }^{6}$ Ello en parte fue reforzado por la presencia de algunos profesores argentinos, es el caso de Víctor Manuel Arroyo ${ }^{7}$ y Augusto Bonazzi, y por la incorporación de ex becarios que habían realizados sus estudios en Argentina (seis) y en Uruguay (cinco). 


\section{El crecimiento de la comunidad venezolana}

Pero en la medida que la comunidad profesional de veterinarios fue creciendo, la relación que en los años de 1930 se había establecido con la región del sur del continente mermó. A mediados de la década de 1940, la tendencia fue enviar a los veterinarios graduados a completar su formación de postgrado en los Estados Unidos (Ruiz Calderón, 1990, 1997). Ya para ese entonces, la medicina veterinaria que en sus inicios había estado bajo la tutela del MAC, era parte de la Universidad Central de Venezuela al crearse la Facultad de Ciencias Veterinarias con sus respectivos institutos de investigación en 1948.

La mayor parte de los profesionales de la veterinaria trabajaban al servicio del Estado venezolano como funcionarios del MAC (1936) en las distintas dependencias relativas al área pecuaria, entre ellas el Instituto de Investigaciones Veterinarias creado en $1940 .{ }^{8}$ Un grupo más pequeño se ocupaba de las actividades universitarias de formación, investigación y divulgación. En la construcción de este perfil profesional habían contribuido los veterinarios extranjeros a través de la docencia, la investigación, la creación de revistas científicas y de asociaciones científicas. En el ínterin los profesionales venezolanos habían alcanzado las posiciones de responsabilidad en las oficinas estatales que en los inicios, cuando se empezaron a crear los servicios de veterinaria, estuvieron a cargo de los extranjeros (Freites, 1999).

Respecto al impacto de la veterinaria en la sociedad venezolana, lentamente la idea de una sanidad animal fue siendo divulgada por los agentes del gobierno ligados a la producción agropecuaria ${ }^{9}$, así como por diferentes asociaciones de productores, que cual sociedades ilustradas de entonces ${ }^{10}$, mantenían revistas destinadas a la divulgación de los saberes prácticos teniendo por fuente a profesionales, técnicos e investigadores de la veterinaria, especialmente los de origen extranjero.

A principios de de la década de 1940, en el Instituto de Investigaciones Veterinarias se había podido elaborar la vacuna de la encefalomielitis equina tipo Venezuela cuando el checo Kubes y el venezolano Ríos identificaron el virus específico (1939) (Kubes, Rios, 1939). ${ }^{11}$ Pero fue a inicios la década de 1950 cuando la medicina veterinaria en Venezuela hubo de enfrentarse a una situación que demandó de ella conocimiento, experticia y habilidades de campo para salvar el rebaño nacional. Se trata de un episodio de carácter regional como fue el surgimiento de la fiebre aftosa y punto de partida de las relaciones con México.

\section{La aftosa, esa enfermedad lejana}

La fiebre aftosa, conocida desde tiempo inmemorial, es una enfermedad altamente contagiosa que ataca casi exclusivamente a los animales de pezuña hendida domésticos y salvajes $^{12}$; a éstos se les forma vesículas o ampollas en la mucosa bucal y nasal y en la piel situada encima y en medio de las pezuñas, así como en las ubres. En 1546 fue descrita por primera vez por el italiano Fracastorius y para entonces ya se había propagado por Francia e Inglaterra. En 1898 se aisló el virus causante, presente en la saliva de un animal enfermo; pero luego se descubre que hay una pluralidad de virus. ${ }^{13}$ Así en 1922, Vallée y Carré en 
Yajaira Freites

Francia identificaron dos tipos distintos del virus, distinguiendo los serotipos Vallée O (aislado en Oise) y Vallée A (aislado en Ardennes en animales provenientes de Alemania). En 1926, Waldmann y Trautwein, en Isee Reims (Alemania), reconocieron una tercera variedad del virus que se denominó Waldmann C. Más tarde, en 1948, cepas proveniente de África fueron estudiadas por Brooksby quien descubrió los serotipos SAT-1 (Souther African Territories) procedente de Bechualanand y el SAT-2 de Rodesia. ${ }^{14}$

Se presume que la aftosa fue traída a la América cuando españoles y portugueses introdujeron el ganado bovino. Desde 1870 se la había identificado en Argentina (Pérez, 1994, p.70-76), en la región central de Chile, en el Uruguay y en sur del Brasil, coincidiendo con el surgimiento de la misma en la costa noreste de Estados Unidos. Dado la pasividad de los gobiernos latinoamericanos, la epizootia se extendió a Chile, Perú, Bolivia y Paraguay (Correa Meio, López, 2002). A finales de los años de 1940, Perú sufrió un brote (Angulo, 1947). Hasta los años de 1950, en América Latina, sólo Venezuela junto con Colombia y Ecuador eran territorios libres de aftosa. Pero esto no iba seguir así por mucho tiempo; en 1950 Venezuela y en 1952 Colombia experimentaron la epizootia y en 1961, Ecuador. ${ }^{15}$

De acuerdo a las publicaciones venezolanas de la época, nos encontramos que hay noticias de la aftosa antes del episodio que nos interesa destacar. En un extenso artículo publicado en el órgano divulgativo del MAC, El Agricultor Venezolano, creado en 1937 $(\mathrm{OGG}, 1939)^{16}$, da cuenta del primer brote. El autor pretendía exponer de manera sencilla la existencia de esta enfermedad: los diversos nombres con los cuales era conocida (glosopeda, fiebre aftosa, afta epizoótica o estomatitis aftosa infecciosa), el origen viral de la misma, los tipos de virus implicados hasta ese entonces conocidos (el $\mathrm{O}$ de origen francés, el A de procedencia alemana y el C); señala que al hallarse el virus en las vesículas, éstas al romperse se mezclaban con lágrimas, saliva y moco nasal, facilitando la contaminación. De igual manera, la orina, la leche y las materias fecales podían ser eficientes medios de propagación del virus. De acuerdo al autor (p.13-14), a los cinco o seis días ocurría la eliminación del virus, aunque se podía comprobar diez o 12 días después de la infección. Durante ese tiempo, la movilización del ganado, en especial en épocas calurosas, permitía el contagio más fácilmente, tanto de la tierra, el agua, los forrajes, los vehículos de transporte; tanto el hombre como las aves contribuían a su propagación. En cuanto a la terapia, menciona al ácido sulfuroso como uno de los mejores medios para destruir el virus. No hay ninguna mención a alguna vacuna. ${ }^{17}$ En cuanto a la erradicación, sólo se hace referencia oblicuamente al indicar que en la experiencia inglesa el Estado hubo de intervenir para indemnizar a los productores por el sacrificio de sus animales; de igual manera se refiere a su aparición en Francia, Alemania e Italia, en esta última dice que había surgido repetidamente a principios del siglo XX. No hay ninguna alusión a la América Latina, y en especial a la Argentina en donde la enfermedad era endémica desde mediados 1870 (Correa Meio, López, 2002; Zabala, 2005). El articulista venezolano indica que uno de los descubridores del virus es el francés Henry Vallée, quien recientemente había dado conferencias sobre el particular en la Universidad de Buenos Aires.

Dos años más tarde, en el mismo medio, El Agricultor Venezolano, se publica un trabajo corto relativo a otra enfermedad que suele confundirse con la aftosa, la estomatitis aftosa o estomatitis vesicular (Novicky, 1941). Se trata del informe de un investigador de origen 
checo que trabajaba en el Instituto de Investigaciones Veterinarias en visita a la provincia de Barinas con el fin de estudiar casos de estomatitis vesicular infecciosa en animales domésticos que se había extendido por la región en proporciones alarmantes. El especialista, en compañía del médico veterinario de la medicatura de la zona, hace una inspección en los diferentes animales, toma muestras y acompaña en diversos ensayos al veterinario local, quien en una publicación posterior da cuenta de los resultados. Termina su informe indicando las diferencias que tendría con la aftosa y como esa enfermedad no estaría presente en los diversos animales examinados.

En el ámbito académico, la Revista de Medicina Veterinaria y Parasitología ${ }^{18}$ reporta en 1941 el estudio de un tratamiento de la estomatitis seudo-aftosa a base de creolina (Delgado Vivas, 1941). En ese mismo número hay un artículo referente a las principales afecciones bacterianas por ultravirus y parasitarias de mamíferos y aves domésticas en Venezuela; los autores reportan la ya conocida estomatitis vesicular (Gallo, Vogelsang, 1941, p.161).

Del examen de las publicaciones divulgativas como científicas que existían para ese entonces en el país, observamos que la fiebre aftosa era declarada como extraña en el país. Los divulgadores se limitan a dar información acerca de la enfermedad de acuerdo a la literatura conocida y a ahuyentar el alarma que pudiera haber cundido con el surgimiento de la estomatitis vesicular que por algunas de sus características puede ser confundida con la aftosa. No hay referencias a vacunas porque todavía las existentes se percibían como poco seguras o porque los contactos con los centros europeos se habían interrumpido a causa de la Segunda Guerra Mundial. Hasta ese entonces, los europeos se habían ocupado más del asunto.

La inquietud sobre la aftosa en Venezuela empezó a tener bases cuando, en 1945, el gobierno de la Junta Cívico-Militar había tomado la decisión de importar carne congelada desde la Argentina, lo cual ocasionó un debate al interior del mismo gobierno. Tanto el propio ministro del MAC, como el director de ganadería, quienes debían sus puestos al nuevo grupo gobernante, se opusieron a la medida. Ellos consideraron que era un riesgo para el país. No obstante, la importación se hizo y ambos funcionarios renunciaron.

Ese incidente dio lugar a que en junio de 1945 la Asociación Nacional de Ganaderos de Venezuela (ANGV) solicitara al despacho la anulación de la importación, dado la existencia de la aftosa en Argentina. A raíz de ello, la Junta Directiva de la Asociación hizo una serie de consultas a centros científicos de diversos países de América acerca de la enfermedad y sus medios de contagio (ANGV, 1946-1947). Cuando la importación ocurrió, la Asociación, en enero de 1947, solicitó al MAC información acerca de las medidas que se habían tomado para prevenir la epizootia en cuestión.

\section{México en la mira}

A finales de 1946 y principios de 1947, una comisión de la Corporación Venezolana de Fomento, encabezada por el ganadero Julio de Armas, también presidente de la ANGV, había realizado un viaje por la región sur de los Estados Unidos y México a fin de comprar ejemplares para la ganadería del país. En declaraciones a la prensa capitalina, el presidente de la Asociación había indicado la conveniencia de adquirir ganado mexicano ya que 
Yajaira Freites

existía "una zona subtropical que ofrece una serie de características climatológicas y ecológicas más o menos similares a algunas de las regiones de nuestra zona pecuaria" (Ante el brote..., 1946-1947, p.4), además de ser un tipo de ganado mas adaptable al medio venezolano, amén de los precios discutidos que resultaron más equitativos para los productores venezolanos (p.4-5). Durante su estancia en tierras aztecas, dos días antes de su regreso a Venezuela, el ganadero reconocía que había tenido noticias veladas sobre la aparición de la epizootia por lo publicado en un periódico que se refería a una estomatitis benigna, curable y pasajera. Salvo por esta información, ningún asunto había trascendido en sus conversaciones con los ganaderos con quien negociaba, así como con los funcionarios de la Secretaria de Agricultura de México pues al parecer la enfermedad estaba siendo objeto de identificación. En la frontera sur de los Estados Unidos, la comisión había visto como toretes procedentes de México pasaban a tierras norteamericanas. Pero era obvio que cuando llegaron a Caracas, la noticia de la aftosa en México era pública y notoria ${ }^{19}$, razón por la cual la compra de ganado mexicano quedó cancelada (p.5, 1946-1947).

Con información fresca, en enero 3 de 1947, la ANGV a través de una carta al ministro de Agricultura y Cría, le solicita una entrevista a fin de exponerle la posición de la Asociación respecto al brote de fiebre aftosa en México, su decisión de paralizar la importación de caballos procedentes de dicho país, así como indagar acerca de las medidas de control y vigilancia que el despacho había tomado en la isla La Orchila (Venezuela) donde estaban alojados unos cebúes importados del Brasil (ANGV, 1946-1947). En otra comunicación del mismo mes (8 de enero) se reitera la oposición a la importación de animales mexicanos, especialmente caballos, "a fin de evitar la contaminación del virus mediante los forrajes y otras medidas de contagio" (ANGV, 1946-1947). El despacho contestó las comunicaciones de los ganaderos en una extensa carta a la Asociación (8 de enero de 1947) donde detalla las medidas de control y vigilancia que había tomado en la isla La Orchila con el ganado cebú (Mendoza Goiticoa, 1946-1947, p.2-4); pero no se indica ninguna decisión acerca de cesar la importación de ganado y caballos de México, lo cual parece extraño dado que un periódico de circulación nacional publica la noticia sobre el cese de las importaciones de ganado vacuno mexicano.

Es posible que ante el silencio del gobierno, la Asociación haya optado por dar una alarma a través de su publicación Revista Pecuaria (1946-1947), órgano de la Asociación creado en 1938, en cuyo editorial manifiesta su oposición a que se importe ganado y sus derivados donde la aftosa está presente (Editorial..., 1946-1947).

De acuerdo a la carta del encargado del MAC, las autoridades venezolanas habían sido cautelosas (Mendoza Goiticoa, 1946-1947). A finales del año 1946 habían buscado confirmar las noticias de la enfermedad en México. ${ }^{20}$ Solicitaron recabar información al personal venezolano destacado en el norte, tal como el veterinario Enrique Vogelsang y el agrónomo Martín de Moya que se hallaban en México. Otro tanto hace en los Estados Unidos, el veterinario Gustavo Rivas Larralde, un ex becario en el Uruguay. También se indaga ante el jefe del Bureau de Industria Animal del Departamento de Agricultura de Estados Unidos (p.2-3). No obstante, las únicas declaraciones acerca de la prohibición de la importación de animales procedentes de México y de Brasil son las dadas por Armas a la prensa. Luego un periodista indaga directamente ante el ministro, quien se limita repetir parte de la información que diera a los ganaderos sin referirse a la prohibición (Caracteres..., 1946-1947). 
El Ministerio de Agricultura y Cría, en una muestra de solidaridad latinoamericana, organiza el envío de un grupo de médicos veterinarios para que den su concurso en la situación que enfrentan los colegas mexicanos (Caracteres..., 1946-1947). Si bien la comunidad de veterinarios en Venezuela era de implantación reciente, la mayor parte de sus integrantes se había formado en Argentina y Uruguay y aquellos que realizaron su adiestramiento en el país lo hicieron con expertos contratados procedentes de esas regiones. De buenas a primera se pudiera pensar que había en el país una capacidad científica para prevenir o hacer frente a la epizootia. La visita a México podía dar otra información, especialmente con el manejo de una campaña que pudiera ser útil si la situación llegara a presentarse.

La campaña mexicana fue un escenario de la confluencia de expertos procedentes de los Estados Unidos, Chile, Inglaterra y por supuesto Venezuela. Holanda, Suiza y Dinamarca contribuyeron enviando litros de vacuna (Mayer, 1988, p.118). Pero a la par hubo otras interesantes experiencias.

En el campo de la formulación de una vacuna específica, ya en diciembre de 1946, un grupo de veterinarios mexicanos reunidos en Puebla lograron aislar el virus identificado como MP (México-Puebla). ${ }^{21}$ La preparación de la vacuna se hizo con el concurso de los expertos argentinos Rosembuch y Blanck ${ }^{22}$ y del brasileño Silvio Torres ${ }^{23}$ quienes usaron una variación de la vacuna argentina Rosembuch, que era una modificación de la alemana Waldmann (Mayer, 1988, p.118).

De acuerdo a Mayer (1988, p.118-119), el virus detectado en México resultó ser el mismo que apareció en Brasil (pero no indica cual), aunque con algunas variaciones. En cualquier caso, la vacuna 'mexicana' tenía una serie de ventajas sobre las importadas, además de ser específica al virus desplegado en México. Así por ejemplo, las enviadas por Holanda, al descongelarse por las precarias condiciones del medio rural mexicano, fueron más dañinas que benéficas. El virus sufrió una reversión aumentando su virulencia. Otras requerían para ser inyectadas de unos 20cc en tanto la nacional se aplicaba con menos de $5 \mathrm{cc}$.

La aplicación de la vacuna a finales de 1947 puede considerarse como la segunda fase de la campaña mexicana, sustituyendo al rifle sanitario, el cual ocasionó brotes de insurrección y ocasionó la muerte de brigadistas a manos de campesinos reticentes a permitir el sacrificio de sus animales (Mayer, 1988, p.119, 121). Ciertamente el esfuerzo de vacunación a gran escala realizado en México permitió constatar que la vacuna constituía un control efectivo y radical contra la epizootia.

\section{La algarabía de la prensa venezolana}

La prensa venezolana se hizo eco del problema de la aftosa en México y así la Revista Pecuaria reproduce noticias acerca de unos cebúes brasileños que después de haber pasado con éxito la cuarentena de la isla de Sacrifico (México), y del examen de los expertos técnicos norteamericanos y mexicanos, al ser liberados aparecen en los informes cablegráficos como diseminadores de la enfermedad (Ante el brote..., 1946-1947; El grave peligro..., 1946-1947). ${ }^{24} \mathrm{El}$ asunto del origen o procedencia de la enfermedad llevó en aquel entonces a achacar que el ganado mexicano había sido infectado por reses procedentes del Brasil, lo 
Yajaira Freites

cual ocasionó que periodistas y articulistas en Venezuela también se pronunciaran por la importancia de prohibir el ganado procedente de ese país. ${ }^{25}$

Esas notas, como otras que se reproducen en la misma revista, disertan acerca de la tragedia nacional que la epidemia tiene para la ganadería mexicana, describen lo que fue la primera parte de la campaña mexicana - basada en el rifle sanitario - que llevó al sacrificio de centenares de animales, el papel de las brigadas de veterinarios y peritos, como las cuarentenas establecidas (Caracteres..., 1946-1947). ${ }^{26}$ Por supuesto hay demandas sobre la necesidad de que Venezuela ejecute fielmente las medidas preventivas, aparte de terminar con la importación de animales de países con aftosa, entre ellos de Brasil (Desde mi atalaya..., 1946-1947; Los ganaderos..., 1946-1947; El grave peligro..., 1946-1947; Malas perspectivas..., 1946-1947), el cumplimiento de las cuarentenas, las consecuencias devastadoras que la epidemia tendría si atacara el rebaño nacional (Carvajal Madrid, 1946-1947). Todos apuntan a la necesidad de una decisiva intervención de las autoridades del Ministerio de Agricultura y Cría para evitar el surgimiento de la epizootia en Venezuela (Desde mi atalaya..., 1946-1947; El grave peligro..., 1946-1947; Carvajal Madrid, 1946-1947).

\section{El aséptico mundo académico}

Durante todo el año 1947, el MAC no generó ninguna información sobre el desarrollo de la enfermedad en México. En El Agricultor Venezolano solo se inserta un artículo sobre la estomatitis vesicular en la provincia de Barinas, el cual había sido escrito por el veterinario de la medicatura en la zona. En el artículo se ratifica lo ya sabido: la estomatitis no es aftosa (Basterrechea, 1947).

Pero el mundo de la academia tiene otra cara. En otra revista científica de la época, Revista Grancolombiana de Zootecnia, Higiene y Medicina Veterinaria ${ }^{27}$, se encuentran reseñas acerca de la aftosa circunscritas a la transcripción de un artículo sobre la resistencia al virus de la fiebre aftosa (Vallée, 1947); luego en la sección Revista de Revista, que eran resúmenes de información a cargo de la División de Información Técnica de la Dirección de Ganadería del MAC (Venezuela, 1947a, 1947b, 1947c), se incluyen noticias de las disposiciones legales preventivas adoptadas por Bélgica y Uruguay contra la aftosa, así como datos sobre sueros y vacunas. Es la primera vez que se menciona la existencia de vacunas y de experiencias con ellas a cargo de Vallée y de Waldmann. Estas últimas informaciones parecen más destinadas a la actualización del conocimiento de los integrantes de la comunidad de veterinarios en el país. Pronto habría noticias de la experiencia mexicana a través de una colaboración académica entre los profesores y veterinarios, el uruguayo-venezolano Vogelsang y el mexicano Manuel Chavarría.

\section{La conexión académica mexicana y argentina}

Enrique Guillermo Volgelsang (1897-1969), de origen uruguayo, se había establecido en Venezuela a principios de los años 1930 y era una de las figuras pioneras de la medicina veterinaria en Venezuela. Para el momento en cuestión se desempeñaba como director de la Escuela Superior de Veterinaria en Venezuela, pero a la par llevaba a cabo investigaciones 
principalmente en el campo de la parasitología. También - junto con otro extranjero, el italiano Piero Gallo -, era el fundador de la Revista de Medicina Veterinaria y Parasitología. Su contraparte mexicana, Manuel Chavarría (1909-1991), era veterinario con estudios en biología y también se dedicaba a la investigación en parasitología; en los años 1940 participaba activamente en la campaña de la fiebre aftosa (Cervantes, 2002).

No están claras las circunstancias y detalles del encuentro de Vogelsang con Chavarría, pero en 1947, ambos publican un trabajo sobre la aftosa en México (Vogelsang, Chavarría, 1947). Este texto merece atención especial porque es una mezcla de aspectos generales de la situación mexicana, de la campaña que está en marcha, como de detalles científicos (desinfección de los vehículos con soda cáustica, capa de cal sobre los restos de los animales sacrificados, uso del licor de Forgue) y del saber popular acerca de la enfermedad. ${ }^{28} \mathrm{Se}$ insertan numerosas fotografías relativas a los distintos aspectos reseñados. No es un trabajo relacionado con experimentos ni muestra estadísticas; narra la forma como el gobierno mexicano ha tratado de afrontar la peste y el concurso de los expertos y las medidas de indemnización a los productores por las reses sacrificadas. Al final se indica que el virus tipo Vallée A ha sido identificado.

En los años siguientes la Revista de Medicina Veterinaria y Parasitología sigue manteniendo el interés en el problema de la aftosa en México. En 1948 incluye el trabajo experimental de dos argentinos sobre resultados hematológicos en los animales en el período post-vacunal contra la fiebre aftosa (Rottgardt, Lanusse, 1948). Tiene al principio una revisión de los hallazgos reportados en la literatura (que incluye a autores en Argentina) para luego dar cuenta de una parte experimental propia donde detalla las técnica y el experimento que consiste en utilizar distintos tipos de vacunas, dosis y vías de administración (intradérmica y subcutánea) a diez grupos de bovinos. El trabajo es presentado como parte de las actividades del Instituto Nacional de Fiebre Aftosa de Argentina.

Al año siguiente, en la misma revista, Chavarría (1949) contribuye con un artículo sobre el diagnóstico y determinación de la fiebre aftosa. En su artículo se refiere a las actividades de la Unidad de Prueba y Tipificación creada por la Comisión MexicanaNorteamericana Para la Erradicación de la Fiebre Aftosa en México; dicha unidad tenía a su cargo el diagnóstico de la aftosa, de la estomatitis vesicular con la cual a veces era confundida la primera; también realizaba la tipificación de un virus de aftosa ya cuando las lesiones eran muy extensas o cuando la variante producía mayor o menor inmunidad; como parte del asunto también se tipificaba el virus de la estomatitis. La Unidad permitía conocer con precisión si los brotes se debían a la aftosa o no y en consecuencia tomar medidas adecuadas para su control en caso que fuere así. Es un trabajo que incorpora los esquemas de trabajo de los distintos diagnósticos y tipificaciones; también nos permite conocer que el virus tipo A era el que había sido identificado en México. El artículo de Chavarría termina indicando que en la próxima entrega se referirá al diagnóstico y la determinación del tipo por medio de la fijación de complementos. ${ }^{29}$

En la entrega de la revista de 1950 serán los argentinos Rottgardt ${ }^{30}$ y Charles (1950) quienes publicaran un texto tratando el diagnóstico y la determinación del tipo por medio de la fijación de complementos. Ellos describían detalladamente la preparación de los distintos reactivos para la tipificación del virus por fijación de complementos. ${ }^{31}$ También 
Yajaira Freites

en ese mismo número se incluye otro artículo que versa sobre control de los productos usados en la inmunidad pasiva relacionados con la aftosa (Rottgardt, 1950). En este texto, Rottgardt hace una revisión de las técnicas ideadas entre 1897 a 1942 por diversos investigadores europeos, norteamericanos y latinoamericanos ${ }^{32}$ destinadas a determinar la actividad preventiva del suero antiaftoso. Termina con una serie de indicaciones acerca de cómo hacer la titulación o determinación del compuesto de un suero monovalente para el virus tipo O Vallée. La contribución de Chavarría se desvía de la aftosa al publicar un trabajo relacionado con la parasitología (Chavarría, 1950). Otro artículo de ese número de la revista es autoría de Vogelsang (1950) quien escribe un breve obituario sobre el mexicano Isaac Ochotorena, muerto el 12 de abril de 1949, quien trabajara sus últimos años en su laboratorio de histología en la Escuela Nacional de Medicina Veterinaria de México. Los venezolanos, por su parte, se limitan a presentar los resultados de ensayos de inmunidad con el virus de la estomatitis vesicular (Gallo, Lugo, 1950). Han transcurridos dos años desde la alarma en México.

\section{La aftosa llega a Venezuela}

El presentimiento de la Asociación Nacional de Ganaderos tomó cuerpo en 1950. El entonces rector de la Universidad Central de Venezuela, nuestro ya conocido doctor Julio de Armas, envió a dos veterinarios franceses - Henrie Ballot y Daniel Remy Basille - que eran profesores contratados en la Facultad de Veterinaria, a una finca en el estado Lara. ${ }^{33}$ Ellos regresan con el temido diagnóstico y habiendo tomado muestras, éstas son remitidas a los institutos especializados de Inglaterra, Francia y Argentina. Todos confirman la presunción de Ballot y Basille acerca de la presencia de la cepa O de Vallée.

\section{La contribución práctica mexicana}

En el ámbito académico, el primer artículo sobre la aftosa en Venezuela es producto de la relación de Chavarría con Vogelsang, publicado en la Revista de Medicina Veterinaria y Parasitología (Vogelsang, Chavarría, Rosales, 1951). Allí se delinea el inicio de la enfermedad, su expansión en el territorio, las medidas de contención, terapéutica, así como las acciones preventivas mediante la inoculación de la vacuna contra los virus O Vallée y A, presentes en el caso venezolano. Este artículo guarda bastante similitud con el confeccionado acerca de México, aunque en el caso venezolano se puede presentar un mapa de la peste, así como un cronograma más preciso de las alarmas y denuncias que fueron surgiendo, los tipos de virus involucrados y la buena noticia que la inoculación de las reses permitía asegurar - en el corto plazo - el control de la enfermedad.

Por su parte el gobierno venezolano, al decretar la alarma sanitaria en julio de 1950, invitó al país a especialistas destacados en fiebre aftosa tanto de Europa como de América Latina. México correspondió enviando una nutrida delegación de veterinarios encabezada por el licenciado Flores, secretario de Ganadería de la Secretaría de Agricultura y co-presidente de la Comisión Mixta Mexicano-Americana. Entre los mexicanos había aquellos que tenían experiencia trabajando en los laboratorios de diagnóstico y preparación de vacunas en las 
instalaciones de Palo Alto en California, como aquellos que se habían ocupado de las labores de campo durante la campaña (Ruiz Martínez, 1966, p.159-160).

Ciertamente la delegación mexicana participó en la situación de Venezuela. ${ }^{34}$ Una vez que las autoridades venezolanas empezaron a organizar el Instituto de la Fiebre Aftosa (IFA) en 1950 (Venezuela, 1955), éste inicia sus actividades técnicas de la campaña de erradicación y control de la enfermedad con base en el programa elaborado conjuntamente con la misión enviada por México (El virus A..., 1953). El plan implicaba en una primera etapa labores de cuarentena y desinfección y el sacrificio, de manera enérgica, rápida y cuidadosa para evitar la propagación del virus. En una segunda fase se pasaba a la vacunación masiva de todos aquellos animales susceptibles a la epizootia; y una tercera, orientada a producir en casa la vacuna eficiente en cantidades suficientes para la campaña de vacunación (Venezuela, 1952). Dado que el virus tipo O Vallée era el que se manifestaba en Venezuela, de buenas a primera el gobierno tuvo que adquirir los primeros lotes de vacuna mientras se montaban los laboratorios en el país para producirla.

Los laboratorios para elaborar y producir la vacuna fueron instalados en la cercanía de la ciudad de Maracay (centro del país) y quedaron listos en enero de 1951, lográndose a la par el primer lote de vacuna para el virus tipo O Vallée. Esta vacuna se administraba por vía intradérmica y la dosis era $2 \mathrm{cc}$. Al igual que la mexicana, era un potpurrí de tradiciones: se había basado en las técnicas de Waldmann, Schmidt, Rosembusch y en los trabajos experimentales llevados a cabo por Silvio Torres en Brasil, Angel Blank en Argentina y Alfredo Téllez Girón en México a raíz de la aparición de la aftosa en ese país; para su producción contaba con un servicio de producción de coloide (Venezuela, 1952, p.13-14). Para preservar la vacuna, el IFA disponía de un servicio especializado de almacenamiento y transporte refrigerado, así como la dotación de termos refrigerados que permitían a las cuadrillas llevar la vacuna hasta los lugares más lejanos (Venezuela, 1952, p.48).

En El Agricultor Venezolano se insertaron notas editoriales dirigidas al mundo agropecuario instándolo a colaborar con las actividades del IFA, de manera de mantener la colaboración y la disciplina en los métodos de erradicación (Fiebre aftosa, 1951). También se explica la necesidad de declarar dos días a la semana sin carne, así como la prohibición tanto de exportar como importar ganado, vía contrabando desde Colombia, donde ya se había declarado la epizootia, medidas todas destinada a restringir los focos de infección (Editorial, 1952, p.2).

A mediados de 1952 las autoridades venezolanas estaban dispuestas a erradicar la aftosa usando la vacuna. Para ese propósito el gobierno había gastado 15 millones de bolívares y había la disposición de gastar lo que fuera necesario para lograr el objetivo. Los laboratorios del IFA tenían capacidad de producir 1,5 millones dosis de vacunas mensuales (Hadgialy, 1952).

Cuando, a finales de marzo de 1951, el tipo A Vallée apareció en una hacienda de la zona de Puerto Cabello (al centro norte del país) se recurrió a los laboratorios mexicanos, pero éstos ya no tenían existencias (El virus A..., 1953, p.42). Entonces los venezolanos optaron por fabricarlo en el país; crearon un laboratorio de producción en la Estación Cuaternaria en la Hacienda Santa Rosa, en las inmediaciones al sitio del brote. Para 1954, la aftosa perdió su característica de epizoótica y el gobierno juzgó que no había amenaza 
Yajaira Freites

grave. Debido a ello, ese mismo año, se disolvió el IFA y sus labores pasaron a ser desempeñadas por la Dirección de Ganadería del MAC, manteniendo en vigencia las disposiciones de la campaña (Venezuela, 1955, p.5).

\section{Abriendo un camino}

En términos de los datos examinados, las relaciones científicas establecidas por Venezuela, entre los años de 1940 y principios de 1950 corresponden a un momento en que el país tendió a conocer más las experiencias científicas y técnicas de sus vecinos más adelantados. A través de visitas, del envío de becarios y de la contratación de expertos trató de apropiarse del conocimiento y la técnica que requería para sus programas sociales y económicos (Ruiz Calderón, 1997). Si bien se becó personal a los Estados Unidos, a México y a la Zona del Canal de Panamá, hubo disciplinas, como en el caso de la veterinaria y agronomía, en las que se prefirió la formación en Uruguay y Argentina (Ruiz Calderón, 1997). Luego en los años siguientes la tendencia dominante en todas las disciplinas fue la realización de estudios en los Estados Unidos (Ruiz Calderón, 1990).

Tal como se indicó, la influencia de Argentina y Uruguay estaba presente por la formación de los primeros veterinarios del país. Sin embargo esta ascendencia se desvaneció en la medida que no se establecieron otros vínculos más permanentes tal como pudieran haber sido los relativos a la investigación y a la cooperación técnica. Si bien el gobierno venezolano había contratado expertos de países procedentes del Cono Sur, estos venían a titulo personal y no como parte de un convenio de intercambio y asesoría con instituciones de estos países. Obviamente quedaban los nexos de amistad y el conocimiento por parte de los egresados $^{35}$, a quienes, en sus lugares de formación, podían darles ayuda. Es lo que en parte explicaría por qué se remite una muestra al Instituto de Aftosa de Buenos Aires a fin de confirmar el diagnóstico y el tipo de virus de la aftosa.

Al comparar el tipo de contribución que estuvo presente en el caso de la aftosa en Venezuela, se pueden observar dos interesantes hechos. Por una parte está la importancia de Argentina desde el punto de vista de sus capacidades científicas; indicadores de ellas son las publicaciones académicas que hemos encontrado. ${ }^{36}$ Éstas proporcionaron estudios experimentales acerca de los métodos de identificación del virus, el valor inmunológico de los sueros, los efectos posteriores a la vacunación contra la epizootia. En el caso venezolano, todo este acervo tendiente al uso de vacunas y a las posibilidades de controlar la aftosa, funciono como un acopio científico-técnico importante para elaborar su propia vacuna. Pero, paradójicamente, en esa misma época, la capacidad científica de Argentina en el terreno de creación de de vacunas no era usada de manera masiva en la erradicación de la aftosa (Zabala, 2005). ${ }^{37} \mathrm{Y}$ por otra parte, la experiencia mexicana mostraba que ello sí podía hacerse, al usar la vacuna de manera sistemática y amplia. Así los mexicanos que vinieron a Venezuela tuvieron la oportunidad de transferir a sus colegas venezolanos su experiencia científica y técnica a raíz de la campaña contra la fiebre aftosa en la ganadería mexicana.

Sucintamente, los venezolanos parecían contar con profesionales, con formación adquirida en países en donde la aftosa era endémica y, por consecuencia, tenían un 
conocimiento de la misma, pero carecían de la experiencia de erradicarla de manera masiva. Esta era la experticia que podían aprender de los mexicanos. Así, éstos al ayudar a los venezolanos en la planificación y ejecución de la campaña contra la aftosa, les transfirieron los aspectos de la organización y la práctica social que aquellos habían aprendido, en parte a través del ensayo y el error ${ }^{38}$ al luchar contra la aftosa y erradicarla. El ejemplo mexicano era prueba de que podía hacerse. ${ }^{39}$

Así, la conjunción de dos influencias latinoamericanas permitió a Venezuela hacer frente a la aftosa. Pero también hemos podido detectar otra tercera influencia, como es la brasileña, que se habría manifestado a través de los saberes aplicados en México. Pero esto es otra historia.

El escenario de relaciones bilaterales que hemos estudiando, que iban desde lo informal a lo formal, cambió a partir de la década de 1950 para dar lugar a las relaciones científicotécnicas a través de los organismos multilaterales en el campo de la salud animal. En 1951, ante la expansión de la aftosa tanto en el sur como en el norte del continente americano, la Organización de Estados Unidos (OEA) creó el Centro Panamericano de Fiebre Aftosa (Panaftosa) que luego se convirtió en un programa regular de la Organización Panamericana de la Salud (OPS) con sede en Brasil (D’Apice, 1951, p.469-470; Correa Meio, López, 2002). La lucha contra la aftosa, al igual que las enfermedades humanas, pasaría a ser objeto de una colaboración internacional y no el problema de una sociedad afanada por obtener conocimiento y tecnología para erradicarlas.

\section{AGRADECIMIENTO}

Al doctor Jaime Benchimol por sus pertinentes comentarios y observaciones que posibilitaron mejorar el texto. Pero son de mi absoluta responsabilidad los errores y omisiones.

\section{NOTAS}

* In memoriam de Osvaldo Antonio Pérez (24/05/1956-09/05/2007). Fundador y presidente de la Asociación Argentina de Historia de la Veterinaria. Egresó como veterinario de la Universidad de Buenos Aires (1980). A la par del ejercicio de su carrera, se interesó en la historia de la disciplina, obteniendo el titulo de historiador en la Universidad del Salvador (1980). Pionero de la investigación histórica acerca de los orígenes de la veterinaria en Argentina. Gracias a su generosidad pude incorporar a este artículo varios datos.

${ }^{1}$ Nos referimos a los países que en cierto momento histórico, no siendo totalmente desarrollados, se convierten en referencias para otros menos desarrollados debido a que poseen o han demostrado ciertas capacidades científico-técnicas en áreas específicas. En el caso de Venezuela, hay varios ejemplos. La tradición prusiana en los inicios de la formación profesional del ejército venezolano moderno fue producto de la transferencia efectuada a través de la asesoría de un oficial chileno, el coronel Samuel McGill, a principios del siglo XX (McGill, 1978; Ziems, 1979, p.99-104). De igual manera, Perú sirvió de lugar para completar los estudios militares al aceptar cadetes venezolanos en la Escuela de Chorillos. Otro tanto lo hizo la Escuela Militar de Bogotá (Ziems, 1979, p.108-109). Lo mismo ocurre con la influencia francesa en la aviación venezolana (Paredes, 1978). Los estudios de las toxinas de serpientes y la fabricación de los antígenos respectivos en Venezuela comenzaron como producto del aprendizaje de un médico venezolano en la década de los 1930 del siglo XX en el Instituto Vital Brazil de Niterói en Brazil (Archila, 1956, v.2, p.219).

2 Juan Vicente Gómez (1857-1935) formó parte del grupo del Táchira, liderados por Cipriano Castro, que en 1898 se apodera de Caracas, la capital, e instauran un régimen centralista que derrota a los diversos caudillos rivales. Gómez, en 1908, depone a Castro y mantiene sus políticas de centralización así como la 
creación de un ejercito moderno; organiza la Hacienda Pública y se promulgan una serie de leyes que permiten luego la inversión extranjera (norteamericana e inglesa) en el área del petróleo, convirtiéndose en el primer producto de exportación, desplazando las exportaciones agropecuarias, tal como café y los cueros. Gómez, en los primeros años (1908-1912), logra aglutinar a un grupo de intelectuales que mantiene funcionando la maquinaria del Estado, iniciando las primeras políticas en el área de la salud, aunque de manera restrictiva; invierte dinero del Estado en la construcción de carreteras. Luego su gobierno deviene en una dictadura legal, suspendiendo las libertades públicas, encarcelando a sus oponentes y/o causándoles la muerte de manera cruel. Al final de su mandato, permite a sus burócratas empezar la fiscalización de actividad de las empresas petroleras extranjeras a fin de asegurar para el Estado el justo pago de la renta. Muere en su cama en 17 de diciembre de 1935, dejando a un país aparentemente tranquilo pero retrasado. Sobre los aspectos científicos y técnicos durante su gobierno, véase Freites, 1987, 1996; acerca de su significado en la política venezolana se puede consultar a Caballero, 1994.

${ }^{3}$ Egresó como veterinario de la Universidad de Brno, en la antigua Checoslovaquia; fue organizador del Servicio Veterinario Oficial y fundador de laboratorios en Ecuador. Contratado en 1933 por el gobierno venezolano, a través de la Oficina de Cooperación Agrícola de la Unión Panamericana, en 1934 y 1935 , imparte dos veces el Curso de Prácticos en Sanidad Animal. En su enseñanza hace hincapié en el contacto con las realidades ganaderas del país. A la par realiza diagnósticos de las enfermedades del rebaño nacional, dicta clase en la Escuela de Expertos Agropecuarios, realiza actividades en pro de la salud animal. Cuando se crea la Escuela Superior de Veterinaria revalida su título (1940); en 1940 se le solicita la creación y organización del Instituto de Investigaciones Veterinarias, siendo su director hasta 1945; autor de varios artículos científicos, informes y trabajos divulgativos, se tiene noticias de él hasta 1952. Muere en El Salvador (Perry, Cía. Editores, 1952, p.143-144; León, 1996).

${ }^{4}$ Eleazar López Contreras (1883-1973) fue el más joven del grupo tachirense que invadió a Caracas. Desarrolló una intensa y variada carrera pública como militar y como funcionario público; ganó la confianza de Gómez al hacer diversas tareas. A la muerte de él se desempeñaba como ministro de Guerra y Marina, elegido por el Congreso para terminar el período de Gómez y vuelto a elegirse para el lapso 1936-1942. Durante su gestión se inició la modernización del Estado venezolano, orientado a la construcción de infraestructura vial, económica, impulsando la actividad agropecuaria, la puesta en marcha de una extensa política de salud pública, de expansión de la educación primaria y secundaria, de renovación de los estudios universitarios e incorporación de conocimientos y tecnologías en la gestión del Estado. Autodidacta y civilista, entregó la presidencia a otro paisano suyo, elegido por el congreso, Isaías Medina Angarita, quien también continuó sus políticas. Sobre las políticas reformista de López Contreras y el uso de la ciencia véase Ruiz Calderón, 1992.

${ }^{5}$ En 1889, el gobierno de la provincia de Buenos Aires crea la Facultad de Agronomía y Veterinaria, la cual empieza sus clases en 1890; en 1905 fue incorporada a la Universidad Nacional La Plata. Debido a múltiples problemas, entre ellos el descuido de los estudios de veterinaria a favor de los de agronomía, surge la separación y en 1921 se constituye la Facultad de Medicina Veterinaria, denominación que es cambiada en 1951 a Facultad de Ciencias Veterinarias. Por su parte, en la ciudad de Buenos Aires, el Ejecutivo creó en 1904 el Instituto Superior de Agronomía para capacitar adecuadamente personal del país. En 1906, el Instituto es incorporado a la Universidad de Buenos Aires con el carácter de Facultad de Agronomía y Veterinaria. La separación ocurre 1972, surgiendo la Facultad de Ciencias Veterinarias de dicha universidad. Una historia de ambas escuela puede leerse en Pérez, 1994, p.135-144, 175-188, respectivamente.

${ }^{6}$ Siguiendo la pista dada por León (1996, p.116), la autora en una visita de campo a la Facultad de Ciencias Veterinaria de La Plata (1997) pudo constar la similitud del pensum entre las escuelas de La Plata y la de Venezuela en los años de 1938.

${ }^{7}$ Víctor Manuel Arroyo (1891-1976), profesor egresado de La Plata, fue titular de anatomía descriptiva y comparada y de anatomía topográfica en la Facultad de Medicina Veterinaria de La Plata en 1923-1947. Profesor de anatomía y fisiología en la Facultad de Agronomía de La Plata hasta 1947. Junto al doctor Ángel Cabrera creó el Museo de Anatomía Veterinaria de la Facultad, que hoy lleva su nombre. Presidente del Círculo de Médicos Veterinarios de la provincia de Buenos Aires en 1941-1943. Entre sus obras se destaca su Tratado de anatomía descriptiva del caballo. En 1955, debió abandonar la cátedra y partió primero a Chile y después a Venezuela donde continuó su labor docente al incorporarse en el dictado de las cátedras de anatomía descriptiva y comparada de animales domésticos. Murió en Caracas (datos suministrados por Pérez, 1997).

${ }^{8}$ Antes de la creación del Instituto de Investigaciones Veterinarias, en el viejo Ministerio de Salubridad y Agricultura (1932) existían los laboratorios de Bacteriología y Parasitología Veterinarias donde se realizaban 
algunas investigaciones y se había empezado a preparar vacunas. Para ese entonces el checo Kubes se desempeñaba como jefe del Servicio de Investigaciones Veterinarias del MAC; entonces fue natural que luego se le solicitara la creación y organización del Instituto en 1940 (Freites, 1999, p.346-347).

${ }^{9}$ Implicó a Ministerio de Sanidad y Asistencia Social, a propio MAC que tenía una variedad de publicaciones tales como el Boletín Informativo del MAC, el Boletín de la Dirección de Ganadería del MAC, El Agricultor Venezolano, Informaciones Agropecuarias del MAC. Hasta el Banco Agrícola y Pecuario tenía su respectiva revista.

${ }^{10}$ Algunas de ellas eran la Asociación Nacional de Ganaderos de Venezuela, Caracas, con la Revista Pecuaria (1938), la Asociación de Criadores del Distrito Infante (Guárico), cuyo órgano de difusión era El Ganadero: Revista de Divulgación Zootécnica (León, 1996, p.134). La Compañía Ganadera Industrial Venezolana, S.A., si bien era una empresa, mantuvo hasta 1942 la Revista Ganadera.

${ }^{11}$ A finales del siglo XIX, Venezuela había transferido los conocimientos de la bacteriología y la elaboración de vacunas y se había creado el Instituto Pasteur de Caracas (1895-1904), de índole privada, organizada por los médicos venezolanos, donde se preparó el suero antidiftérico (febrero de 1885). Se cultivó en linfa de ternera, el fluido de la viruela. Otro tanto se hizo con el microbio del tétano preparando la toxina respectiva. El Instituto tenía un depósito renovado de sueros antidiftérico, antitetánicos como la vacuna de la viruela para uso inmediato. Ésta última fue fabricada de manera industrial en 1989 a raíz de una epidemia (Rodríguez Lemoine, 1999, p.243-247). Luego, durante el período de Gómez, existió en la Oficina de Sanidad Nacional, el Laboratorio de BCG (1932) destinado a la fabricación de la vacuna de la tuberculosis (Freites, 1996, p.163-165). En 1938, con la creación del Instituto Nacional de Higiene, se busca tener un ente que estudie las enfermedades tropicales y elabore vacunas tanto para uso humano como veterinario (Gutiérrez, 1999, p.131).

${ }^{12}$ La sufren el ganado bovino, ovino, porcino y caprino.

${ }^{13}$ El virus de la aftosa está clasificado como un Aphtovirus perteneciente a la familia Picornaviridae, sensible al $\mathrm{pH}$, conformado por siete serotipos que no proporcionan inmunidad cruzada entre ellos. De allí que la infección por uno de ellos no previene la infección por otro de los indicados. Los serotipos hasta ahora identificados son tipo O, A C, SAT-1, SAT-2, SAT-3 y ASIA-1. Cada una de estos serotipos tiene cepas diferentes entre si, las cuales se agrupan en subtipos de acuerdo a su comportamiento inmunológico. Sólo en América Latina se han identificado 35 subtipos (Panaftosa, s.d.).

${ }^{14}$ En 1953 aparece el SAT-3 en la misma Rodesia; el último, el ASIA-1, fue descubierto en 1957 en Pakistán. (FAO, s.d.).

${ }^{15}$ El avance de la aftosa en América se inicia en 1870 con Argentina, Uruguay, Estados Unidos y Canadá; en 1871, Brasil y Chile; en 1910, Perú; en 1945, México.

${ }^{16}$ Presumimos que el autor era posiblemente uno de los veterinarios extranjeros, quienes en ese período escribieron y publicaron trabajos científicos, reportes y artículos de divulgación (Freites, 1999).

17 Tanto Vallée como Waldmann habían recomendado administrar dosis de suero hiperinmune a los animales susceptibles; ambos, a finales de los años 1920 y 1930 formularon las primeras vacunas; Vallée en 1926 había obtenido buenos resultados con las mismas pero al ser usadas por otros no habían logrado éxito. Walmann al parecer en 1936 tuvo logros mejores. La Oficina Internacional de Epizootias había iniciado en 1941 y puesto a funcionar en 1942 un Instituto en Suiza destinado a producir la vacuna de Waldmann. Similares iniciativas se habían dado en Dinamarca, Porto Alegre (Brasil), a cargo de Sílvio Torres, y en Argentina (Venezuela, 1947c, p.929-930).

${ }^{18}$ Fue la primera revista científica de veterinaria en Venezuela; en ese entonces estaba a cargo de la Escuela y luego de la Facultad de Medicina Veterinaria de la Universidad Central de Venezuela. En la actualidad continúa como Revista de la Facultad de Ciencias Veterinarias.

${ }^{19}$ La prensa mexicana, concretamente El Excélsior de ciudad de México, el 27 de diciembre de 1946, dio a conocer la noticia. El 28 de ese mes se cerró la frontera norte cortándose el flujo de ganado con los Estados Unidos. Y el 29, la prensa anunciaba una cifra millonaria dedicada a erradicar la aftosa (Mayer, 1988, p.116).

${ }^{20} \mathrm{Al}$ parecer en el mismo lapso que Armas y el grupo de la Corporación Venezolana de Fomento hacían las diligencias para la compra de ganado en México.

${ }^{21}$ El grupo estuvo integrado por Alfredo Téllez Girón, Fernando Camargo, Juan Uzuelta Roz, Flores Romero, Gómez y Suárez Michel (Mayer, 1988, p.118). Camargo llevó una muestra al Instituto de Pirbright, en Inglaterra; el informe sobre el particular de Camargo fue publicado en la Revista de la Dirección General de Investigaciones Pecuarias de México y aparece reseñado en D’Apice (1951, p.506). 
22 En la literatura sobre la aftosa para 1951, Rosembuch aparece como autor de trabajos relacionados con la vacuna intradérmica; entre tanto Blanck o Blanc estaba interesado en el comportamiento de sustancias frente al virus así como su conservación (D'Apice, 1951).

${ }^{23}$ Si bien Mayer (1988, p.118) se refiere a Silvio Torres como Silvia, se trata del veterinario brasileño que había desarrollado una vacuna basada en los principios básicos de la de Vallée, Schmidt y Waldmann, la cual usó cuando la epizootia apareció en Rio Grande do Sul, Brasil (D’Apice, 1951, p.470).

${ }^{24}$ De acuerdo a Mayer (1988, p.117) quién entrevistó a expertos mexicanos que actuaron en la campaña de erradicación de la aftosa, ellos concluyeron que efectivamente los toros cebúes procedentes de Brasil con estadía en la isla de Sacrifico, a pesar de estar aparentemente sanos, sí eran portadores del virus, pero el estado de la virología - según ellos - no permitía detectar esta condición oportunamente.

${ }^{25}$ Sobre el origen de la aftosa en México, hay dos posiciones: el origen brasileño a través de los cebúes ya mencionados; véase Montemayor (1984, t.1, p.217-235) y Mayer (1988, p.117). La otra hipótesis sostiene que fue debida a una incubación producto de la exportación del sur pero desde tiempo atrás (Cervantes, 2005). En tal sentido Volgelsang y Cavarría $(1947$, p.3) informan que ya en 1925 se había producido un brote en el estado de Tabasco, concretamente en Puerto Alvaro Obregón, dominado con el rifle sanitario. Posiblemente los cebúes brasileños hayan sido el desencadenante inmediato de la epizootia.

${ }^{26}$ La fase del rife sanitario fue la que se dio a conocer más por la prensa y para nada se menciona la vacunación.

${ }^{27}$ Se trata de una publicación auspiciada por el Ministerio de Agricultura y Cría y que buscaba abarcar la producción bibliográfica de Ecuador, Colombia y Venezuela. La dirigía el médico veterinario español Carlos Ruiz Martínez.

${ }^{28}$ Según Volgensang y Chavarría (1947, p.26-29), los campesinos usaron remedios con los que acostumbran a tratar el 'mal de hierba', utilizando de preferencia, vinagre, limón, bicarbonato de sodio y antisépticos como creolina, azul de metileno o ácido bórico. Estos tratamientos habrían ayudado en el tratamiento de los animales enfermos, ya que el virus de la aftosa es muy sensible a los cambios del pH. En tal sentido también habría obtenido buenos resultados el licor de Forgue por su contenido de ácido pícrico, concomitante al sulfato de cobre, que habría obrado como astringente, y el alcanfor como refrescante, actuando como buen desinfectante, fortificante y rápido cicatrizante.

${ }^{29}$ En la actualidad se usan para identificar el virus aftoso, la Prueba de Elisa, la Reacción en Cadena de la Polimerasa (PCR) y la fijación de complemento (FdC) (FAO, s.d.).

${ }^{30}$ Rottgardt era el director técnico del Instituto Nacional de Fiebre Aftosa en Buenos Aires, Argentina.

${ }^{31}$ La prueba de FdC puede ser utilizada para la cuantificación de anticuerpos tempranos. Para ello se debe mezclar diluciones conocidas del suero con unidades de fijación del complemento específico para la fiebre aftosa (FAO, s.d.).

32 Se trata de los argentinos Rosembusch, Shang, Rossi y Aramendi, como el mismo Rottgardt y el brasileño Braga (Rottgardt, 1950, p.53-54).

${ }^{33}$ Henri Ballot se había graduado en la Escuela de Veterinaria de Alfort. En 1948 el gobierno venezolano lo contrata para enseñar clínica ambulante; en 1949, se encargó de dictar la materia de bacteriología. Regresa a su país en 1950 (León, 1996, p.288). Daniel Remy Basille Baille, también era egresado de Alfordt. Antes de venir a Venezuela fue jefe de Laboratorio en el Servicio Sanitario de París y en el Departamento del Sena (1935-1947). Vino a Venezuela contratado en 1947 para atender las cátedras de Inspección de Productos Alimenticios y Enfermedades Infecto-Contagiosas a tiempo completo. Enviado a Francia, al Instituto de Fiebre Aftosa de Lyon, con el material recogido donde se corroboró el diagnóstico clínico debido al Virus O de Vallé. Luego no hay más noticias del él (León 1999, p.251, 321).

${ }^{34}$ Mayer y Lomnitz (1988, p.70) señalan que la formación de los veterinarios mexicanos, a través de su participación en la campaña contra la aftosa, les permitió asesorar a sus colegas sudamericanos. Uno de los entrevistados en el trabajo indica que formó parte del grupo que fue a Venezuela para atender el mismo problema permaneciendo en el país por seis meses.

${ }^{35}$ Por ejemplo, el director del Instituto de Fiebre Aftosa y el que organizó el Laboratorio de Producción de Vacunas e investigación de Fiebre Aftosa habían realizados sus estudios en Uruguay (Ruiz Martínez, 1966, p.162).

${ }^{36}$ La exploración sobre el particular escapa a los objetivos de este trabajo, pero lo reseñado da cuenta del acervo de conocimientos que la Argentina tenía sobre la aftosa. Ello se constata en parte en la revisión bibliográfica realizada por D'Apice, 1951. 
${ }^{37}$ De acuerdo a Zabala (2005, p.812-815), hubo repetidos esfuerzos del gobierno federal argentino para que los ganaderos vacunasen el ganado pero dichas campañas resultaron infructuosas porque no había un control y supervisión, así como también porque las vacunas elaboradas por los diversos laboratorios no aseguraban la inmunidad debido a la ausencia de un control de calidad, el cual fue asumido luego por el Estado en los años 1990 del siglo XX - durante el mandato del presidente Carlos Raúl Menen como parte de la voluntad política que planificó, ejecutó y supervisó una campaña nacional destinada a erradicarla definitivamente.

${ }^{38} \mathrm{Si}$ bien el rifle sanitario figuraba en la campaña venezolana como una de las medidas, era sólo usado en caso necesario. Esto era un aprendizaje del caso mexicano donde esta práctica había llevado a brotes de rebelión en las zonas rurales. Otro tanto ocurrió con proveer equipos portátiles de refrigeración.

${ }^{39}$ Ruiz Martínez (1966, p.180) así lo indica: "no es posible olvidar el ejemplo dado recientemente por los veterinarios mejicanos [sic] al combatir y vencer de manera terminante la fiebre aftosa que invadió su territorio".

\section{REFERENCIAS}

ANGULO, Ángel.

Experiencias de la campaña anti-aftosa en el sur del Perú. Revista de la Facultad de Medicina Veterinaria, Lima, v.2, n.1-2, p.15-19. 1947.

ANGV.

Asociación Nacional de Ganaderos de Venezuela. Gestiones de la Asociación Nacional de Ganaderos de Venezuela en la campaña de prevención de la fiebre aftosa. Revista Pecuaria, Caracas, n.98-99, p.11. 1946-1947.

ANTE EL BROTE...

Ante el brote de epizootia descubierto en México han sido canceladas las negociaciones para la compra de 10.000 vacunos (reproducción de las declaraciones ofrecidas a La Esfera por el dr. Julio de Armas, presidente de la Asociación). Revista Pecuaria, Caracas, n.98-99, p.4-5. 1946-1947.

ARCHILA, Ricardo.

Historia de la sanidad en Venezuela. 2v. Caracas: Imprenta Nacional. 1956.

BASTERRECHEA, Lucas de.

La estomatitis aftosa o estomatitis vesicular y sus diferencias clínicas y bacteriológicas con la glosopeda o fiebre aftosa. El Agricultor Venezolano, Caracas, n.126, p.35. Este artículo también fue reimpreso en Revista Pecuaria, Caracas, n.98-99, p.15, 1946-1947. 1947.

CABALLERO, Manuel.

Gómez, el tirano liberal. Caracas: Monte Ávila Editores Latinoamericana. 1994.

\section{CARACTERES...}

Caracteres de grave tragedia reviste la fiebre aftosa en el ganado de México (reproducción de nota del diario capitalino El Universal). Revista Pecuaria, Caracas, n.98-99, p.9-10. 1946-1947.

CARVAJAL MADRID, B.

En resguardo de nuestra cría. Revista Pecuaria, Caracas, n.98-99, p.10. 1946-1947.
CERVANTES, Juan Manuel.

Historia y evolución de la fiebre aftosa en México (1946-1955). In: Saldaña, Juan José (Ed.). Proceedings of the XXIst International Congress of History of Science México 2001. Ciudad de México: SMHCT/UNAM, p.753-766. Disponible en: http://www.ivic.ve/ estudio_de_la_ciencia/Simposio\%20de $\% 20$ Enfermedades\%20que\%20afectan...volumen08.pdf. Acceso en : 29 oct. 2006. 2005.

CERVANTES, Juan Manuel.

Dr. Manuel Chavarría Cavaría: un parasitólogo veterinario. In: Congreso Mexicano de Historia de la Ciencia y la Tecnología, 7., 3-6 nov. 2002, Guanajuato. Actas... Guanajuato: s.n.. p.32. 2002.

CHAVARRÍA CH., Manuel.

Fasciola hepática, anomalías en el aparato reproductor femenino. Revista de Medicina Veterinaria y Parasitología, Maracay, v.9, n.1-4, p.69-84.1950.

\section{CHAVARRÍA CH., Manuel.}

Diagnóstico de fiebre aftosa y determinación del tipo. Revista de Medicina Veterinaria y Parasitología, Maracay, v.8, n.1-4, p.17-36, 1949.

CORREA MEIO, Eduardo; LÓPEZ, Alejandro. Control de la fiebre aftosa: la experiencia americana. Revista Científica y Tecnológica de la Oficina Internacional de Epizootias, Paris, v.21. n.3, p. 689-694. 2002.

COTTER, Joseph.

The Rockefeller Foundation's mexican agricultural project: a cross-cultural encounter, 1943-1949. In: Cueto, M. (Ed.). Missionaries of science: the Rockefeller Foundation in Latin America. Bloomington: Indiana University Press. p.97-125. 1994.

CUETO, Marcos (Ed.).

Missionaries of science: the Rockefeller Foundation and Latin America. Bloomington: Indiana University Press. 1994. 
D'APICE, Virginie Buff.

Febre aftosa e vírus aftoso: aspectos e referências bibliográficas. Revista da Faculdade de Medicina Veterinaria, São Paulo: Universidade de São Paulo, v.4, n.3, p.469-508. 1951.

DELGADO VIVAS, Víctor.

La creolina intravenosa en el tratamiento de la estomatitis pseudo-aftosa. Revista de Medicina Veterinaria y Parasitología, Maracay, v.3, n.1-4, p.167-172. 1941.

DESDE MI ATALAYA...

Desde mi atalaya, texto del periódico capitalino La Esfera. Revista Pecuaria, Caracas, n.98-99, p.5. 1946-1947.

\section{EDITORIAL...}

Editorial: vigilancia contra la fiebre aftosa. $E l$ Agricultor Venezolano, Caracas, n.153, p.2. 1952.

EDITORIAL...

Editorial: La fiebre aftosa. Revista Pecuaria, Caracas, n.98-99, p.1. 1946-1947.

\section{EL GRAVE PELIGRO..}

El grave peligro de la fiebre aftosa (reproducción de nota del diario La Esfera. Revista Pecuaria, Caracas, n.98-99, p.6. 1946-1947.

\section{EL VIRUS A...}

El virus A de Vallée en Venezuela. El Agricultor Venezolano, Caracas, n.161, p.40-43. 1953.

ESPINA, Délia Beatriz.

O papel das empresas multinacionais na industrialização periférica: um estudo da trajetória da IBM no Brasil. In: Arboleda, Luis Carlos; Osoro, Carlos (Ed.). Nacionalismo e internacionalismo en la historia de las ciencias y la tecnología en América Latina. Cali: Colombia. p.313-320. 1997.

\section{FAO.}

Organización de las Naciones Unidas para la Agricultura y Alimentación. Fiebre aftosa: enfermedad transfronteriza. Disponible en: http://www.rlc.fao.org/prior/segalim/animal/ aftosa/fa/. Acceso en: 10 ene. 2008. s.d.

FIEBRE AFTOSA.

El Agricultor Venezolano, Caracas, n.149, p.3. 1951.

FITZGERALD, Deborah.

Exporting american agriculture: The Rockefeller Foundation in Mexico, 1943-1953. In: Cueto, Marcos (Ed.). Missionaries of science: the Rockefeller Foundation in Latin America. Bloomington: Indiana University Press. p.72-96. 1994.

FREITES, Yajaira.

La implantación de la medicina veterinaria: el papel de los pioneros extranjeros (1833-1955). Interciencia, Caracas, v.24, n.6, p.344-351.
Disponible en: http://www.ivic.ve/ estudio_de_la_ciencia/Veterinaria.pdf. Acceso en: 14 ene. 2008. 1999.

FREITES, Yajaira.

Auge y caída de la ciencia nacional: la época del Gomecismo (1908-1935). In: Roche, M. (Comp.). Perfil de la ciencia en Venezuela. t.1. Caracas: Fundación Polar, 1996, p.153-198. Disponible en: http://www.ivic.ve/ estudio_de_la_ciencia/Auge.pdf. Acceso en: 3 ene. 2008. 1996.

FREITES, Yajaira.

La ciencia en la época del gomecismo. Quipu, Ciudad de México, v.4, n.2, p. 213-251. 1987.

GALLO, Piero; LUGO, Alberto.

Ensayos de inmunidad activa con el virus de la estomatitis vesiculosa en Acures I. Revista de Medicina Veterinaria y Parasitología, Maracay, v.9, n.1-4, p.117-120. 1950.

GALLO, Piero; VOGELSANG, Guillermo. Sinopsis nosográfica de las principales afecciones bacterianas por ultravirus y parasitaria de los mamíferos y aves domésticas de Venezuela (continuación). Revista de Medicina Veterinaria y Parasitología, Maracay, v.3, n.1-4, p. 157-162. 1941.

\section{GUTIÉRREZ, Ana Teresa.}

Estado y medicina tropical: el Instituto Nacional de Higiene (1938-1960). In: Martín Frechilla, Juan José; Texera, Yolanda (Comp.). Modelos para desarmar: instituciones y disciplinas para una historia de la ciencia y la tecnología en Venezuela. Caracas: Universidad Central de Venezuela; Consejo de Desarrollo Científico y Humanísticos. p.127-149. 1999.

HADGIALY, Miguel.

La aftosa será erradicada totalmente de Venezuela. El Agricultor Venezolano, Caracas, n.154, p.30-31. 1952.

\section{INFORMACIÓN...}

Información de la Compañía Industrial Ganadera Venezolana que fue transmitida por la Broadcasting Caracas el 12 de octubre de 1934, a las 7:30 p.m. Revista Ganadera, Caracas, n.1, p.7. 1934.

\section{JUZGADO DE COMERCIO.}

Documento constitutivo de la Compañía Ganadera Industrial Venezolana. Revista Ganadera, Caracas, n.1, p. 9-12. 1934.

KUBES, Vladimir; RIOS, Francisco A. The causative agent of infectious equine encephalomyelitis in Venezuela. Science, Washington, v.90, n. 2323, p.20-21. 1939.

LA COMPAÑÍA...

La Compañía Ganadera Industrial Venezolana 
y la industria pecuaria nacional. Revista Ganadera, Caracas, n.2, p.11-13. 1934.

LEÓN, José Antonio.

20 años: historia de la Facultad de Ciencias Veterinaria, Universidad Central de Venezuela. Caracas: s.n. 1996.

LOS GANADEROS...

Los ganaderos y la fiebre aftosa (reproducción de texto del diario capitalino El Universal). Revista Pecuaria, Caracas, n.98-99, p.11. 1946-1947.

MALAS PERSPECTIVAS...

Malas perspectivas pecuarias. Revista Pecuaria, Caracas, n.98-99, p.7. 1946-1947.

MAYER, Leticia.

La investigación e innovación tecnológica en situaciones de emergencia: el caso de la fiebre aftosa. Quipu, Ciudad de México, v.4, n.1, p.115-124. 1988.

MAYER, Leticia; LOMNITZ, Larissa. La nueva clase social: desarrollo de una profesión en México. Ciudad de México: Universidad Nacional Autónoma de México. 1988.

MCCOOK, Stuart.

States of nature: science, agriculture, and environment in the Spanish Caribbean (17601940). Austin: University of Texas Press. 2002.

MCCOOK, Stuart.

Promoting the practical: science and agricultural modernization in Puerto Rico and Colombia, 1920-1940. Agricultural History, Minard Hall, v.75, n.1, p. 58-82. 2000.

MCGILL, Samuel.

Poliantea: Memorias del coronel McGill. Caracas: Ediciones de la Presidencia de la República. 1978.

MENDOZA GOITICOA, Eduardo.

Carta al ciudadano presidente de la Asociación Nacional de Ganaderos. Revista Pecuaria, Caracas, n.98-99, p.2-4. 1946-1947.

MONTEMAYOR, Pedro Suacedo. La fiebre aftosa en México: su presentación y erradicación (1946-1957). In: Montemayor, Pedro Suacedo. Historia de la Ganadería en México. 2v. Ciudad de México: Universidad Nacional Autónoma de México. 1984.

NOVICKY, Richard.

La estomatitis vesicular en Barinas. El Agricultor Venezolano, Caracas, n.64, p.31-32. 1941.

O.G.G.

Consideraciones sobre la fiebre aftosa.

El Agricultor Venezolano, Caracas, n.33, p.11-15. 1939.
PANAFTOSA.

Centro Panamericano de Fiebre Aftosa.

Organización Panamericana de la Salud. Enfermedades vesiculares: aftosa. Disponible en: http://www.panaftosa.org.br/Show.aspx?Pg= Menu/intro. Acceso en: 14 ene. 2008. s.d.

PAREDES, Luis $\mathrm{H}$.

Historia de la aviación militar venezolana. Caracas: Corporación Marca. 1978.

PÉREZ, Osvaldo Antonio.

Historia de la veterinaria en el río de la Plata. Buenos Aires: Impresora del Plata S.R.L. 1994.

PERRY, Oliverio; CÍA. EDITORES.

Valores humanos de la Gran Colombia (Venezuela, Panamá, Ecuador y Colombia) con datos recopilados hasta el 30 de junio de 1952. Colombia: Editorial Agra. 1952.

PETITJEAN, Patrick.

Scientific relations as a crossing of supplies and demands science franco-brasilians cases (18701940). In: Lafuente, Antonio; Elena, Alberto; Ortega, Maria Luisa (Ed.). Mundialización de la ciencia y cultura nacional: actas del congreso internacional de ciencia, descubrimiento y mundo colonial. Madrid: Doce Calles. p.635649. 1992.

PYSENSON, Lewis.

Cultural imperialism and exact sciences: german expansion overseas (1900-1930). History of Science, Cambridge (UK), n.20, p.1-43, 1982.

RODRÍGUEZ, Luis Cipriano.

Gómez: agricultura, petróleo y dependencia. Caracas: Tropykos. 1983.

RODRÍGUEZ LEMOINE, Vidal.

Los inicios de la investigación biomédica en Venezuela: el Instituto Pasteur de Caracas. In: Martín Frechilla, Juan José; Texera, Yolanda. (Comp.). Modelos para desarmar: instituciones y disciplinas para una historia de la ciencia y la tecnología en Venezuela. Caracas: Universidad Central de Venezuela y Consejo de Desarrollo Científico y Humanísticos. p.219-255. 1999.

ROTTGARDT, Abel Ángel.

Control de los productos usados en la inmunidad pasiva. Suero, plasma, sangre total. Revista de Medicina Veterinaria y Parasitología, Maracay, v.9, n.1-4, p.41-54. 1950.

ROTTGARDT, Abel Ángel; CHARLES, Eduardo Gabriel.

Preparación de los distintos reactivos para la tipificación por fijación del complemento del virus de la fiebre aftosa. Revista de Medicina Veterinaria y Parasitología, Maracay, v.9, n. 1-4, p.29-40. 1950. 
ROTTGARDT, Abel Ángel; LANUSSE, Juan MARIO.

Algunas observaciones sobre variaciones sanguíneas numéricas de la serie blanca en el período post-vacunal contra la fiebre aftosa. Revista de Medicina Veterinaria y Parasitología, Maracay, v.7, n.1-4, p.9-34. 1948.

RUIZ CALDERÓN, Humberto.

Tras el fuego de Prometeo: becas en el exterior y modernización en Venezuela (1900-1996). Caracas: Nueva Sociedad. 1997.

RUIZ CALDERÓN, Humberto.

La ciencia y la tecnología y el programa de febrero. In: Freites, Yajaira; Texera, Yolanda

(Comp.). Tiempos de cambio: la ciencia en Venezuela (1936-1948). Caracas: Fondo

Editorial Acta Científica Venezolana. p.19-76. 1992.

RUIZ CALDERÓN, Humberto.

Una vieja historia. Los becarios de Venezuela en el exterior (1900-1954). Interciencia, Caracas, v.14, n.1, p.8-14.1990.

RUIZ MARTÍNEZ, Carlos.

Veterinaria venezolana: treinta años de fomento ganadero, sanidad animal e higiene veterinaria (1936-1966). Caracas: Editorial Sucre. 1966.

\section{SAFFORD, Frank.}

The ideal of the practical: Colombia's strugle to form a technical elite. Austin: The University of Texas Press. 1976.

SAFFORD, Frank.

In search of the practical: colombian students in foreing lands (1845-1890). Hispanic American Historical Review, Durham, v.52, n.2, p.230-249. 1972.

VALLÉE, Henry.

Resistencia del virus aftoso. Revista

Grancolombiana de Zootecnia, Higiene y Medicina

Veterinaria, Caracas, v.1, n.10-11-12, p.722-778. 1947.

VENEZUELA.

Ministerio de Agricultura y Cría .

Departamento de Fiebre Aftosa. Lucha contra la fiebre aftosa en Venezuela. Caracas: MAC/ Dirección de Ganadera/División de Sanidad Animal. 1955.

\section{VENEZUELA}

Ministerio de Agricultura y Cría. Instituto de la Fiebre Aftosa. Laboratorio del Instituto de la Fiebre Aftosa. Maracay: MAC. 1952.

VENEZUELA.

Ministerio de Agricultura y Cría. División de
Información Técnica de la Dirección de Ganadería del MAC. La lucha contra la fiebre aftosa en el Uruguay - ley n.10.701. Revista Grancolombiana de Zootecnia, Higiene y Medicina Veterinaria, Caracas, v.1, n.10-12, p.918-920. 1947a.

\section{VENEZUELA.}

Ministerio de Agricultura y Cría. División de Información Técnica de la Dirección de Ganadería del MAC. Vacuna obligatoria contra la fiebre aftosa en Bélgica, por la Dirección Veterinaria belga. Revista Grancolombiana de Zootecnia, Higiene y Medicina Veterinaria, Caracas, v.1, n.10-12, p.921. 1947b.

\section{VENEZUELA.}

Ministerio de Agricultura y Cría. División de Información Técnica de la Dirección de Ganadería del MAC. La vacuna Waldmann contra la fiebre aftosa. Revista Grancolombiana de Zootecnia, Higiene y Medicina Veterinaria, Caracas, v.1, n.10-12, p.928-933. 1947c.

VOGELSANG, Enrique Guillermo.

In memoriam: profesor dr. Isaac Ochotorena. Revista de Medicina Veterinaria y Parasitología, Maracay, v.9, n.1-4, p.153. 1950.

VOGELSANG, Enrique Guillermo; CHAVARRÍA $\mathrm{CH}$., Manuel.

La fiebre aftosa en México. Revista de Medicina Veterinaria y Parasitología, Maracay, v.6, n.1-4, p.3-32. 1947.

VOGELSANG, Enrique Guillermo;

CHAVARRÍA, Manuel; ROSALES, G. Horacio. La fiebre aftosa en Venezuela. Revista de Medicina Veterinaria y Parasitología, Maracay, v.9, n.1-4, p.47-53. 1951.

ZABALA, Juan Pablo.

Capacidad científica y políticas públicas: Historia de la lucha antiaftosa en Argentina. Simposio Enfermedades que afectan a los animales que consumimos. In: Saldaña, Juan José (Ed.). Proceedings of the XXIst International Congress of History of Science México 2001.

Ciudad de México: UNAM-SMHCT. p.802-816. Disponible en: http://www.ivic.ve/ estudio_de_la_ciencia/Simposio\%20de $\% 20$ Enfermedades\%20que\%20afectan...volumen08.pdf. Acceso en: 7 ene. 2008.

ZIEMS, Angel.

El gomecismo y la formación del ejército nacional. Caracas: Editorial Ateneo de Caracas. 1979. 